\title{
PENGARUH MASTERY EXPERIENCE DAN PERSUASI SOSIAL TERHADAP PENINGKATAN SELF-EFFICACY PEGAWAI PADA INSTANSI BADAN PERENCANAAN PEMBANGUNAN DAERAH KABUPATEN DELI SERDANG
}

\author{
Nahar Maganda Saragih \\ Fakultas Ekonomi dan Bisnis, Program Studi Manajemen, Universitas Potensi Utama, \\ Jl. K.L.Yos Sudarso, Tj. Mulia, Medan Deli, Kota Medan-20241 Telp: (061) 6640525, \\ E-mail: naharmagandasaragih@gmail.com
}

\begin{abstract}
ABSTRAK
Dalam semua sektor atau sebuah pembagian daerah administratif yang lazim dipakai di berbagai negara telah banyak lembaga yang menerapkan faktor diluar permasalahan internal menjadi perhatian khusus sebagai upaya guna mendongkrak loyalitas seorang pekerja. Upaya-upaya inilah yang menjadi salah satu aspek sumber daya manusia yang berkualitas. Mastery experience dan persuasi sosial dapat dikelompokkan menjadi atribut-atribut pembangun dan pendongkrak dari selfefficacy seorang pekerja. Dikarenakan dari faktor-faktor inilah secara efektif lembaga atau organisasi diharapkan dapat mengembangkan self-efficacy. Dalam Era hari ini ilmu pengetahuan disebar luaskan dari berbagai akses atau knowledge sharing. Lewat knowledge sharing inilah yang menimbulkan lahirnya perilaku atau sikap berbagi pengetahuan pekerja. Salah satu faktor yang memicu perilaku knowledge sharing yaitu kepercayaan seseorang akan kemampuan yang dimilikinya atau efikasi diri. Dalam penelitian ini banyaknya jumlah dari populasi yaitu berjumlah 76 pegawai. Adapun dalam penelitian ini teknik analisis data yang digunakan adalah Regresi Linier Berganda. Kesimpulan dalam penelitian ini menunjukkan dari segi parsial dan simultan mastery experience dan persuasi sosial memiliki pengaruh terhadap self-efficacy. Dan mastery experience dan persuasi sosial mampu mempengaruhi self-efficacy yaitu sebesar $88 \%$ pada pegawai Bappeda Daerah Kabupaten Deli Serdang
\end{abstract}

Kata Kunci: Mastery Experience, persuasi sosial dan self-efficacy

\section{ABSTRACT}

In all sectors or an administrative area that is commonly used in various countries, there have been many institutions that apply factors outside of internal problems to be of particular concern in an effort to boost the loyalty of a worker. These efforts are one aspect of quality human resources. Mastery experience and social persuasion can be attributes of builders and boosters of a worker's self-efficacy. Due to these factors, the institution or organization is expected to effectively develop self-efficacy. In today's era, knowledge is disseminated from various accesses or knowledge sharing. Through this knowledge sharing, the behavior or attitude of sharing knowledge of workers is born. One of the factors that trigger knowledge-sharing behavior is one's belief in stealing abilities or selfefficacy. In this study, the total population was 76 employees. The data analysis technique used in this study is Multiple Linear Regression. The conclusion in this study shows that in terms of partial and simultaneous mastery of experience and social persuasion have an influence on self-efficacy. And the mastery of experience and social persuasion is able to affect self-efficacy, which is $88 \%$ of the employees of the Regional Development Planning Agency, Deli Serdang Regency

Keywords: Mastery Experience, social persuasion and self-efficacy 


\section{PENDAHULUAN}

Pegawai adalah bagian dari atribut yang mampu menjadi komponen-komponen pendukung keberhasilan cita-cita organisasi. Organisasi memerlukan pegawai yang mampu membantu tugas dan pekerjaan organisasi. Pegawai yang diharapkan dalam sebuah organisasi yaitu seorang pekerja yang produktif dan cekatan dalam menyelesaikan tugas, hal ini menjadi tuntutan kepada pegawai untuk dapat menjadi pekerja dapat didayagunakan secara optimal sehingga keberadaannya dapat dirasakan dan bermanfaat bagi organisasi. Guna menempuh target-target tersebut organisasi sangat bergantung pada pegawai untuk mengolah keahlian dalam memperdalam pengetahuan, keahliannya, maupun sikap. Hal ini dibutuhkan guna produktivitas dari para pegawai dapat bertambah. Pegawai yang memiliki kecekatan dalam menyelesaikan pekerjaan akan mampu mendorong target kerja sehingga akan mampu meningkatkan benefit terhadap organisasi.

Tercapainya susunan rangkaian perencanaan kerja bersumber dari metode-metode pegawai dalam menyelesaikan target kerja, yang diawali dari susunan, metode penyelesaian, pemecahan masalah sampai kepada output kerja yang dihasilkan. Dorongan-dorongan dalam pencapaian kerja yang tinggi ini tidak terlepas dari sugesti atau pengelolaan pemikiran individu itu sendiri terhadap apa yang iya kerjakan. Kondisi ini mengharuskan pegawai mampu mengarahkan pikiran-pikiran nya pada keyakinan yang positif. Namun pikiran-pikiran positif ini tetap mempunyai landasan dalam membuat kesimpulan. Dimana pengalaman dari pegawai dalam menguasai sesuatu yaitu history masa lalu. Jika pengalaman dari masa lalu menghasilkan kegagalan hal ini akan berdampak pada rendahnya selfefficacy dan sebaliknya. Itulah mengapa pentingnya pelatihan atau evaluasi diri rutin dilakukan perusahaan guna meminimkan tingkat kesalahan kerja pegawai sehingga saat pelaksanaan mampu mencapai hasil yang maksimal. Kondisi itu akan berdampak pada kepercayaan diri yang dapat memupuk self-efficacy yang tinggi.

Terdapat empat sumber dari munculnya self-efficacy yang dimulai dari adanya pengalaman yang sudah dijalani oleh seseorang sehingga menimbulkan opini dan persepektif dalam pengambilan sikapnya, kemudian modeling yang dapat dijadikan pedoman atau panduan dalam mengambil keputusan dan sikap sampai kepada persuasi sosial yang mana dalam persuasi sosial ini didorong oleh adanya pengaruh dari lingkungan ataupun orang sekitar.

Mastery experience atau pengalaman dalam menguasai sesuatu pada dasarnya dapat meningkatkan dan dapat pula merendahkan tingkat self-efficacy pada pegawai. Kondisi ini tergolong wajar sebab pengalaman pegawai pada saat mengalami kegagalan dalam menyelesaikan sesuatu akan menjadi pengalaman yang berdampak pada caranya berfikir dan merespon kemudian pegawai akan menganggap bahwa rendahnya kemampuan dirinya pada bidang yang telah gagal dilaksanakan tersebut dan peristiwa ini secara langsung menjadi penyebab rendahnya self-efficacy pegawai. Mastery experience dapat diminimkan lewat pelatihan dan pengembangan yang dilakukan organisasi dimana semakin seringnya pegawai mengikuti pelatihan ini akan meningkatkan kemampuannya dalam pengetahuan dan praktik pekerjaannya. Pelatihan ini jarang dilaksanakan terutama dalam hal pengembangan yang diluar dari pekerjaan sehingga pegawai kurang mengenali kemampuan dalam dirinya.

Pengaruh lain dalam menambah tingkat self-efficacy pegawai yaitu arahan atau bimbingan dari lingkungan sosialnya dimana persuasi sosial akan menyebabkan perubahan keyakinan, perilaku, dan sikap pegawai. Ketika pegawai menerimanya, maka pegawai tersebut akan memperoleh informasi, edukasi yang berdampak pada caranya berfikir sebab persuasi atau arahan sosial akan merangkum segala proses yang mengadung pesan yang berisi makna. Masalah yang menyangkut tentang persuasi sosial sering dikaitkan dengan dukungan-dukungan dan masukan serta motivasi berupa arahan yang diperoleh pegawai baik itu dari atasan maupun rekan kerja. Minimnya arahan ini di indikasikan menjadi pemicu kuat menjadi penyebab rendahnya self-efficacy pegawai. Hal ini diduga tingginya independensi dan persaingan pada pegawai Bappeda Daerah Kabupaten Deli Serdang sehingga menyebabkan kurangnya keakraban dan kekompakan sesama pegawai. Kondisi jelas berdampak pada persuasi sosial, dimana seharusnya dalam persuasi sosial sesama pegawai mampu memberi arahan, baik itu berupa motivasi maupun dukungan sehingga pada apa yang pegawai anggap tidak mampu untuk diterapkan menjadi sesuatu yang mudah untuk dilaksankan. Namun hal ini tidak diperoleh dikarenakan kuatnya budaya individualistik yang terjadi di pada pegawai Bappeda Daerah Kabupaten Deli Serdang 


\section{A. Rumusan Masalah}

1. Apakah mastery experience berpengaruh positif signifikan terhadap self-efficacy pegawai pada pegawai Bappeda Daerah Kabupaten Deli Serdang

2. Apakah persuasi sosial berpengaruh positif signifikan terhadap self-efficacy pegawai pada pegawai Bappeda Daerah Kabupaten Deli Serdang

3. Apakah mastery experience dan persuasi sosial berpengaruh positif signifikan terhadap selfefficacy pegawai pada pegawai Bappeda Daerah Kabupaten Deli Serdang

\section{B. Tujuan Penelitian}

Adapun dalam penelitian ini bertujuan untuk:

1. Untuk dapat mengetahui pengaruh faktor mastery experience terhadap self-efficacy pada pegawai Bappeda Daerah Kabupaten Deli Serdang

2. Untuk dapat mengetahui persuasi sosial terhadap self-efficacy pada pegawai Bappeda Daerah Kabupaten Deli Serdang

3. Untuk dapat mengetahui mastery experience dan persuasi sosial terhadap self-efficacy pada pegawai Bappeda Daerah Kabupaten Deli Serdang

\section{LANDASAN TEORI}

\section{Mastery Experience}

\section{a. Mastery Experience}

Mastery experience adalah sebuah pencapaian dalam bentuk prestasi yang sudah diraih dimasa lampau. Sebuah cerita pengalaman pada masa lampau dapat menjadi pemicu perubahan self-efficacy sebab pengalaman yang baik, positif dan menyenangkan dapat meningkatkan ekspektasi dan angan-angan menjadi pondasi kuat dalam menghasilkan pemikiran-pemikiran yang positif dan self-efficacy yang tinggi. Namun tidak semua pengalaman baik atau mastery experience yang menyenangkan dapat meningkatkan selfefficacy, self-efficacy hanya akan berdampak ketika pencapaian yang diperoleh sesorang memang berasal dari dirinya sendiri dan bukan dikarenkan faktor-faktor dari luar dirinya seperti bantuan orang lain. Sebaliknya apabila pencapaian tersebut diperoleh dari perjuangan yang tinggi, pengorbanan yang besar dan berdasarkan perjuangan sendiri, maka hal ini akan memberi dampak yang sangat tinggi terhadap self-efficacy seseorang.

\section{b. Tingkatan Mastery Experience}

Tingkatan mastery experience menurut Alwisol (2016) yaitu:

1) Semakin sulit tugas maka self-efficacy semakin tinggi

2) Kerja sendiri lebih meningkatkan self-efficacy dari pada kerja kelompok

3) Usaha tinggi hasil rendah self-efficacy rendah

4) Usaha rendah hasil tinggi self-efficacy tinggi

\section{Persuasi Sosial}

\section{a. Pengertian Persuasi Sosial}

Persuasi sosial merupakan sebuah tindakan arahan dan bimbingan yang mana didalamnya terdapat hal-hal yang berisi informasi tentang kemampuan yang disampaikan secara verbal atau nasehat dari atasan atau rekan kerja pegawai. Nasehat tersebut umumnya digunakan dalam membuat seseorang yakin bahwa ia memiliki kemampuan dalam menyelesaikan sebuah persoalan dalam tugas. Pada situasi ini rasa percaya yang tinggi dari seseorang terhadap pemberi nasehat atau bimbingan sangat mempengaruhi hasilnya. Dalam rangka meningkatkan efikasi diri melalui persuasi sosial, dapat menjadi lebih efektif hanya bila kegiatan yang ingin didukung untuk 
dicoba berada dalam jangkauan perilaku seseorang.Sebanyak apa pun persuasi verbal dari orang lain tidakdapat mengubah penilaian seseorang mengenai kemampuan dirinya

\section{b. Unsur-unsur Persuasi Sosial}

Indikator dalam mengukur dari faktor persuasi sosial dapat dikelompokkan menjadi beberapa bagian yaitu:

1) Persuader

Persuader merupakan seseorang atau kumpulan yang menginformasikan pesan dengan maksud memberi pengaruh mengenai sikap, pendapat dan perilaku orang lain baik secara langsung maupun tidak langsung.

2) Persuadee

Persuadee merupakan seseorang atau kumpulan yang menjadi objek pesan disampaikan/disalurkan oleh komunikator/persuader baik secara secara langsung maupun tidak langsung.

3) Pesan Persuasif

Pesan persuasif dipandang sebagai upaya sadar dalam mempengaruhi sugesti dan perilaku dengan motif-motif ke arah tujuan yang sudah ditentukan. Makna dari perilaku fiktif tidak seluruhnya menjadikan fakta lain seperti mengurangi atau menambahkan pada yang nyatanya terjadi bukanlah mengurangi atau menambahkan fakta sesusai konteksnya, akan tetapi dalam makna menggunakan fakta yang berkaitan dengan motif khalayak sasaran. Sehingga terdorong untuk mengikuti isyarat pesan yang disampaikan kedalam dua, yaitu besar dan kecilnya ruang lingkup tugas pokok pada instansi atau lembaga, di mana instansi atau lembaga yang tinggi dan mempunyai jaringan yang besar memerlukan sangat banyak data dan informasi yang memang wajib diselesaikan dari pada instansi atau lembaga yang kecil.

4) Saluran persuasive

Poin ini adalah moderator apabila individu persuade mengalihkan kembali pesan yang berasal dari sumber awal untuk tujuan akhir. Channel yang digunakan oleh persuader guna bertukar informasi dengan semua orang, secara langsung ataupun secara langsung, dan secara resmi atau pun tidak secara resmi.

5) Umpan balik dan Efek

Pada poin ini yaitu umpan balik yang merupakan balasan atau respon yang bersumber dari yang berkomunikasi atau yang berasal dari pesan itu sendiri, poin ini tersusun menjadi dua kategori yaitu dari dalam dan dari luar atau yang biasa disebut dari internal dan eksternal. Umpan balik dari dalam yaitu respon dari komunikator atau pesan yang diutarakan sebagai alat koreksi atas pesan yang telah diutarakan/diucapakan. Selain umpan balik dari dalam terdapat juga umpan balik dari luar yaitu respon yang dilakukan komunikator sebab pesan yang sudah disampaikan oleh komunikan sebagai tanggapan pesan yang diutarakan respon dipahami atau tidak sesuai dengan keinginan atau harapannya.

\section{Self-Efficacy}

a. Pengertian Self-Efficacy

Self-Efficacy merupakan keyakinan dalam diri sendiri terkait kemampuan yang dimiliki diri sendiri, sejauh mana kemampuan yang dimiliki yang dapat berfungsi terhadap situasi tertentu. Self-Efficacy berkorelasi dengan persepsi diri bahwa secara individual mampu melakukan sesuatu yang bermanfaat dan bernilai. Keyakinan ini dapat muncul dari pengalaman dalam meraih atau menghasilkan sesuatu, pengalaman orang lain dan situasi yang terjadi dalam lingkungan keseharian. Self-Efficacy mempunyai peran kuat dalam proses pengaturan melalui arahan dan motivasi orang lain dan target kerja yang telah ditentukan. Deliberasi dalam self-efficacy turut serta menentukan sejauh mana upaya yang telah dilakukan seseorang dalam menyelesaikan pekerjaanya dan berapa lama waktu dalam proses penyelesaiannya. Lebih lanjut dijelaskan bahwa seseorang dengan 
deliberasi self-efficacy yang tinggi akan mampu mempergunakan upaya terbaiknya dalam menyelesaikan persoalan. Dan sebaliknya seseorang dengan tingkat self-efficacy yang rendah kemungkinan besar akan mencari alasan untuk menghindar dalam menghadapi hambatan yang ada.

\section{b. Dimensi Self-Efficacy}

Indikator dalam mengukur dari Self-Efficacy menurut Sopiah (2016) yaitu:

\section{1) Magnitude}

Berpedoman pada taraf kesulitan pekerjaan yang dipercayai individu mampu untuk menyelesaikannya. Tinggi rendahnya tingkat self-efficacy seseorang tidak sama antara satu dengan yang lain. Kesulitan dari sebuah pekerjaan, apakah sulit atau tidak akan menentukan tingkat self-efficacy. Pada sebuah pekerjaan, apabila tidak ditemukan sebuah hambatan yang berat untuk diselesaikan, maka pekerjaan itu akan dengan mudah dikerjakan dan dalam diri seseorang dengan sendirinya akan tumbuh selfefficacy yang tinggi. Sederhananya pekerjaan tersebut sudah dapat teratasi dari awal atau sudah terprediksi

2) Generality

Berpedoman pada banyaknya jenis kondisi dimana perhitungan mengenai self-efficacy dapat diimplementasikan. Seseorang dapat memperhitungkan kemampuannya pada satu jenis pekerjaan saja. Maka dari itu semakin tinggi jenis pekerjaan yang dapat diselesaikan maka akan semakin tinggi pula self-efficacy.

3) Streght

Dimensi streght berkaitan dengan kemampuan seseorang saat dihadapkan pada persoalan dengan tuntutan pekerjaan. Self-efficacy yang rendah dapat dengan mudah dihilangkan dengan pengalaman yang menggelisahkan ketika menghadapi sebuah tuntutan pekerjaan. Dimensi ini mencakup pada tingkat kemantapan seseorang terhadap kepercayaannya. Kemantapan inilah yang dapat mengarahkan serta menentukan ketahanan self-efficacy seseorang

\section{Kerangka Berfikir}

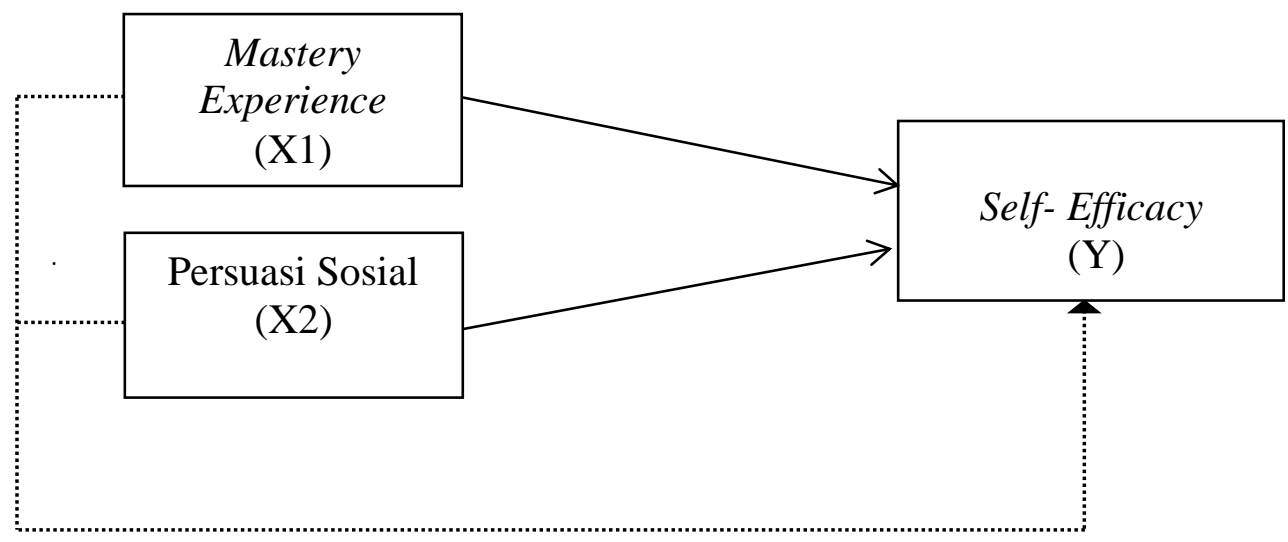

Gambar 1. Kerangka Berfikir

\section{Hipotesis}

1. $\mathrm{H}_{1}$ : Mastery experience memiliki pengaruh yang positif dan signifikan terhadap selfefficacy pegawai Bappeda Daerah Kabupaten Deli Serdang

2. $\mathrm{H}_{2:}$ Mastery experience tidak memiliki pengaruh yang positif dan signifikan terhadap self-efficacy pegawai Bappeda Daerah Kabupaten Deli Serdang

3. $\mathrm{H}_{3}$ : Persuasi sosial memiliki pengaruh yang positif dan signifikan terhadap selfefficacy pegawai Bappeda Daerah Kabupaten Deli Serdang 
4. $\mathrm{H}_{4}$ : Persuasi sosial tidak memiliki pengaruh yang positif dan signifikan terhadap selfefficacy pegawai Bappeda Daerah Kabupaten Deli Serdang

5. $\mathrm{H}_{5:}$ Mastery experience dan persuasi sosial memiliki pengaruh yang positif dan signifikan terhadap self-efficacy pegawai Bappeda Daerah Kabupaten Deli Serdang

6. $\mathrm{H}_{6}$ :Mastery experience dan persuasi sosial tidak memiliki pengaruh yang positif dan signifikan terhadap self-efficacy pegawai Bappeda Daerah Kabupaten Deli Serdang

\section{METODOLOGI PENELITIAN}

\section{Jenis dan Sifat Penelitian}

Dalam penelitian ini jenis penelitian yang digunakan yaitu deskriptif kuantitatif yang mana metode penelitian ini mengandung unsur pendeskripsian suatu fenomena, kejadian, gejala yang disusun secara valid, akurat dan sistemasits.

\section{Populasi dan Sampel}

a) Populasi

Adapun jumlah dari populasi pada penelitian ini yaitu seluruh pegawai Bappeda Kabupaten Deli Serdang sebanyak 76 pegawai.

\section{Instrumen Pengukuran}

Adapun pengukuran yang digunakan yaitu instrument dengan ukuran interval. Ukuran interval adalah skala yang difungsikan untuk mengukur sebuah golongan atau kategori yang mana ukuran tersebut mampu menghasilkan otput yang memberi angka dan dapat diperhitungkan serta menjadi ukuran untuk menyatakan sebuah kategori. Berikut skor penilaian

Skor 1 untuk menyatakan sangat tidak setuju

Skor 2 untuk menyatakan tidak setuju

Skor 3 untuk menyatakan setuju

Skor 4 untuk menyatakan sangat setuju

\section{Jenis dan Sumber Data}

\section{a) Data Utama atau Data Primer}

Adapun data primer merupakan data yang bersumber dari tempat penelitian. Misalnya seperti profil perusahaan, arsip pengelolaan pegawai dan data yang berkaitan dengan variabel penelitian

b) Data Pendukung atau Data Sekunder

Adapun data pendukung yang diperoleh dari pihak eksternal yang mana data ini diperoleh dari pihak ekternal dan memiliki korelasi kepada penelitian untuk mendukung data-data primer. Contohnya seperti penelitian terdahulu, buku dan artikel.

\section{Metode Pengumpulan Data}

Berikut metode-metode yang dilakukan dalam rangka pengumpulkan data:

\section{a) Wawancara}

Dalam wawancara peneliti berusaha memperoleh informasi penting terkait permasalahanpermasalahan yang terjadi pada fenomena sebagai bentuk penjelasan, perolehan informasi yang berguna untuk menemukan titik dasar permasalahan. Dan Tanya jawab ini dilakukan secara lansgung terhadap pegawai Bappeda Daerah Kabupaten Deli Serdang 


\section{b) Studi Dokumentasi}

Studi dokumentasi dilaksanakan bertujuan untuk mempelajari lebih dalam lagi mengenai permasalahan penelitian atau dengan kata lain sebagai data-data pendukung terkait halhal yang mungkin dilewatkan sewaktu wawancara. Pada praktiknya, proses dari pembelajaran dokumentasi ini dilakukan dengan mencari sampai dengan pengumulan data dan menganalisis data tersebut

\section{c) Angket/ Kuisioner}

Kuesioner merupakan teknik pengumpulan data yang tidak kalah penting dilakukan peneliti. Dimana dalam kuesioner terdapat serangkaian pernyataan-pernyataan yang telah dirangkai dan disusun guna mengetahui secara langsung bagaimana persepsi atau opini responden atau pegawai mengenai variabel yang diteliti dan pendapat atau opini responden dapat mengikuti dan disesuaikan dengan skor skala interval yang telah ditentukan.

\section{HASIL DAN PEMBAHASAN}

\section{Hasil Uji Normalitas}

Hasil uji normalitas dengan pendekatan Kolmogorov-Smirnov

Tabel 1. Uji Normalitas

One-Sample Kolmogorov-Smirnov Test

\begin{tabular}{llr} 
& & $\begin{array}{r}\text { Unstandardize } \\
\text { d Residual }\end{array}$ \\
\hline $\mathrm{N}$ & Mean & 76 \\
\cline { 2 - 3 } Normal Parameters & Stb. Deviation & 3.47825250 \\
\hline Most Extreme Differences & Absolute & .127 \\
\cline { 2 - 3 } & Positive & .127 \\
\cline { 2 - 3 } & Negative & -.196 \\
\hline Kolmogorov-Smirnov Z & & .496 \\
\hline Asymp. Sig. (2-tailed) & & \\
\hline a. Test distribution is Normal. & \\
b. Calculated from data. & & \\
c. Lilliefors Significance Correction. &
\end{tabular}

Dapat dilihat bahwa data terdistribusi dengan normal. Hal ini dapat dilihat berdasarkan nilai (Sig) lebih besar dari 0,05

\section{Hasil Uji Regresi}
a. Hasil Uji T

Tabel 2. Uji Regresi Berganda

Hasil Uji Regresi Berganda

\begin{tabular}{|l|c|c|c|c|c|}
\hline \multicolumn{7}{|c|}{ Coefficients $^{\text {a }}$} \\
\hline \multirow{3}{*}{ Model } & \multicolumn{2}{|c|}{$\begin{array}{c}\text { Unstandardized } \\
\text { Coefficients }\end{array}$} & $\begin{array}{c}\text { Standardized } \\
\text { Coefficients }\end{array}$ & & \\
\cline { 2 - 4 } & B & Std. Error & Beta & t & Sig. \\
\hline
\end{tabular}




\begin{tabular}{|c|l|r|r|r|r|r|}
\hline 1 & 19.600 & 2.803 & & 6.992 & .000 \\
\cline { 2 - 6 } & (Constant) & .354 & .067 & .415 & 5.262 & .000 \\
\cline { 2 - 6 } & Mastery experience & .368 & .087 & .383 & 4.247 & .000 \\
\hline \multicolumn{2}{l}{ persuasi sosial } & & & \\
\hline
\end{tabular}

Sumber: Hasil Penelitian, 2021 (Data diolah)

Dari hasil uji regresi berganda dapat dilihat persamaan sebagai berikut yaitu:

$$
\mathrm{Y}=19,600+0,354 \mathrm{X} 1+0,368 \mathrm{X} 2+\mathrm{e}
$$

1. $\beta_{0}=19,600$

Dimana dengan penjelasan yaitu:

Konstanta $\beta_{0}$ bernilai 3,783 hal ini mempunyai makna bahwa keberadaan mastery experience dan persuasi sosial memiliki nilai sebesar 19,600.

2. $\beta_{1}=0,354$

Konstanta bernilai 0,354 menjelaskan bahwa apabila variabel mastery experience meningkat satu satuan, maka variabel self- efficacy akan meningkat sebesar 0,354

3. $\beta_{02}=0,368$

Konstanta bernilai 0,368 menjelaskan bahwa apabila variabel persuasi sosial meningkat satu satuan, maka variabel self-efficacy akan meningkat sebesar 0,368.

\section{b. Hasil Uji F}

Berdasarkan hasil pengolahan data diperoleh nilai uji seremak (Uji F) sebagai berikut:

Tabel 3. Hasil Uji Regresi Berganda Mastery Experience dan Persuasi Sosial (Simultan)

\begin{tabular}{|rl|r|r|r|r|r|}
\hline \multicolumn{2}{|l|}{ Model } & \multicolumn{1}{|c|}{ Sum of } & & & \\
& & Squares & df & Mean Square & F & \multicolumn{1}{c|}{ Sig. } \\
\hline 1 & Regression & 261.784 & 3 & 80.563 & 31.723 & $.000^{\mathrm{a}}$ \\
& Residual & 209.521 & 63 & 3.246 & & \\
& Total & 471.305 & 69 & & & \\
\hline
\end{tabular}

a. Predictors: (Constant), Faktor Non Organisasional, Faktor Personal, Faktor Organisasional

b. Dependent Variable: Komitmen Organisasi

Dari hasil anova dapat diketahui bahwa nilai $F$-hitung sebesar 31.723 dengan tingkat signifikan 0,000 lebih kecil dari alpha 0,05. $F$-hitung yang dihasilkan sebesar 31.723 lebih besar daripada $F_{\text {-tabel }}$ yaitu 2,31. Dengan demikian secara simultan pada variabel mastery experience dan variabel persuasi sosial berpengaruh positif dan signifikan terhadap selfefficacy.

3. Hasil Koefisien Determinasi $\left(\mathbf{R}^{2}\right)$

Tabel 4. Hasil Uji Koefisien Determinasi $\mathbf{R}^{2}$ Model Summary ${ }^{b}$

\begin{tabular}{|l|r|r|r|r|}
\hline Model & \multicolumn{1}{|c|}{$\mathrm{R}$} & R Square & \multicolumn{1}{c|}{$\begin{array}{c}\text { Adjusted R } \\
\text { Square }\end{array}$} & $\begin{array}{c}\text { Std. Error of the } \\
\text { Estimate }\end{array}$ \\
\hline 1 & $.994^{\mathrm{a}}$ & .882 & .799 & .53468 \\
\hline
\end{tabular}

a. Predictors: (Constant), Mastery Experience, Persuasi Sosial

b. Dependent Variable: Self- Efficacy 
Koefisien determinasi mastery experience dan variabel persuasi sosial dapat memberikan dampak sebesar $88 \%$ terhadap self- efficacy. Kondisi ini memperlihatkan bahwa terdapat faktor lain yang menjadi indikasi atau faktor yang memperngaru self- efficacy misalnya seperti awareness atau civic vitue

\section{KESIMPULAN}

1. Setelah dilakukan pengolahan data yang disusun dalam hasil, dapat diketahui bahwa Mastery experience berpengaruh positif dan signifikan terhadap self-efficacy. Hal ini dapat dilihat dari perolehan nilai uji $\mathrm{T}$ dengan hasil sig $0,000<0,05$. Memang dalam banyak penelitian dikemukanan bahwa mastery experience merupakan faktor utama dalam meningkatkan selfefficacy. Hal ini diindikasikan karena self-efficacy dapat bertumbuh dari dalam diri seseorang dikarenakan apa yang telah iya alami dalam proses pekerjaan nya, kehidupan sehari-hari dan lingkungan. Sehingga dari memori tersebut seseorang dapat mengukur kemampuannya.

2. Pada pengujian variabel kedua yaitu persuasi sosial dapat dilihat pengujian menghasilkan nilai sig sebesar $0,000<0,05$. Dapat disimpulkan bahwa persuasi sosial juga memiliki dampak terhadap self-efficacy. Sesuai dengan teori yang mana persuasi sosial merupakan arahan, motivasi ataupun bimbingan dari orang luar yang dapat mengarahkan seseorang untuk menggali kemampuannya. Pesan-pesan atau amanah yang disampaikan dari satu orang terhadap orang lain terkait dengan kemampuannya, dapat meningkatkan self-efficacy yang tinggi kepada orang yang menerima arahan tersebut.

3. Secara simultan Mastery experience dan persuasi sosial berpengaruh terhadap self-efficacy. Hal ini dapat dilihat dari nilai dari tabel anova dengan nilai sig sebesar $0,000<0,05$ yang mana dapat disimpulkan bahwa secara bersama-sama variabel mastery experience dan persuasi sosial berpengaruh signifikan terhadap self-efficacy

\section{DAFTAR PUSTAKA}

[1] Alavi, Bahrami, Boroujeni, \& Yousefy. 2015. Pediatric nurses' perception of factors associated with caring self efficacy.

[2] Ariani. 2011. Hubungan Antara Pengalaman dengan Efikasi Diri Pasien DM Tipe 2 dalam Konteks Asuhan Keperawatan di RSUP H. Adam Malik Medan. Tesis. Depok : Fakultas Ilmu Keperawatan Universitas Indonesia

[3] Aziz Alimul, Hidayat. 2007. Metode Penelitian dan Teknik Analisis Data. Jakarta: Salemba Medika

[4] Gibson, James,L. 2000. Organisasi, Perilaku, Struktur dan Proses. Edisi ke-5. Cetakan ke3

[5] Colquitt, Jason A., Jeffery A. LePine., Michael J. Wesson. 2009. Organizational Behaviour. New York: McGraw-Hill International Companies

[6] Feist, J., \& Feist, G. 2008. Theories of Personality. Edisi 6. Yogjakarta: Pustaka Pelajar.

[7] Hasibuan, H. 2007. Manajemen Sumber Daya Manusia. Jakarta : Bumi Aksara

[8] Ilyas, Y. 2011. Pengalaman, Persuasi Sosial Terhadap OCB. Depok : Pusat Kajian Ekonomi Kesehatan Fakultas Kesehatan Masyarakat Universitas Indonesia 
[9] Lutifi, A.F., Susilo, C., \& Rohmah. 2015. Hubungan Lama Masa Kerja Tenaga Kesehatan dengan Kemampuan Triase Hospital di Instalasi Gawat Darurat RSUD Dr. Abdoer Rahem Situbondo Kabupaten Situbondo.

[10] Mangkuprawira, Sjafri. 2013. Manajemen Sumber Daya Manusia Strategik. Bogor : Ghalia Indonesia

[11] Newstrom, John W., Davis, Keith. 2007. Perilaku Dalam Organisasi. Edisi Ke tujuh. Erlangga : Jakarta.

[12] Nurul. 2015. 5 Kemampuan dan Pengalama yang Harus Mendarah Daging Saat Jadi Perawat

[13] Guna Meningkatkan Self-Efficacy Dalam Pelayanan di IGD.

[14] Siagian, (2010), Job characteristic and quality of working life in the IT workforce: The role of gender Article.

[15] Simbolon, A. M. 2016. Pengaruh Kompetensi dan Pelatihan Terhadap Self-Efficacy Perawat Intalasi Gawat Darurat Di RSU Dr. FL Tobing Kota Sibolga.

[16] Sujatno, (2016), Manajemen Personalia, Ghalia Indonesia, Surabaya

[17] Tjiptono, (2010), Perilaku Organisasi, Bumi Aksara, Jakarta

[18] Tohard, (2010), Teori-teori Pengembangan Sumber Daya Manusia Dalam Pedidikan, PT. Refika Aditama, Bandung

[19] Tangkuman, (2015), Manajemen Perilaku Organisasi, Kencana, Bandung Panggabean, Mutiara S. Manajemen Sumber Daya Manusia. Jakarta: Ghalia Indonesia.

[20] Pajares, F. 2016. "Current Directions in Sel-efficacy Research. Advances In Motivation and Achievement. Reseach Emory University. Avaible (online): 12 Mei 2021

[21] Prestiana, N. D., \& Purbandini, D. 2012. Hubungan antara Efikasi Diri (Self Efficacy) dan Stres Kerja dengan Kejenuhan Kerja (Burnout) pada Perawat IGD dan ICU RSUD Kota Bekasi.

[22] Warsito, Hadi. 2014. Hubungan Antara Self-Efficacy Dengan Penyesuaian Akademik Dan Prestasi Akademik. Jurnal Psikologi pendidikan . Vol.2. September 2014.

[23] Widodo, (2015). Manajemen Sumber Daya Manusia, Zifatama Publisher, Sidoarjo

[24] Wibowo. 2016. Perilaku dalam Organisasi. Jakarta: Rajawali Pers. 